\title{
High proficiency of colonic endoscopic submucosal dissection in Europe thanks to countertraction strategy using a double clip and rubber band $\square$
}

\section{(ㄷ)(우우}

\author{
Authors \\ Institutions \\ 1 Gastroenterology and Endoscopy Unit, Dupuytren \\ University Hospital, Limoges, France \\ 2 Bio-Em, Xlim CNRS UMR 7252 Limoges, France \\ 3 Pathology Division, Dupuytren University Hospital, \\ Limoges, France \\ 4 Gastroenterology and Endoscopy Unit, Pavillon L, \\ Edouard Herriot Hospital, Lyon, Hospices Civils de Lyon, \\ France \\ 5 Pathology Division, East Hospital Group, Hospices Civils \\ de Lyon, France \\ 6 Inserm U1032, Labtau, Lyon, France \\ 7 Statistic Department, Lariboisière Hospital, APHP, Paris \\ France
}

Jérémie Jacques ${ }^{1,2}$, Aurélie Charissoux ${ }^{3}$, Pierre Bordillon ${ }^{1}$, Romain Legros ${ }^{1}$, Jérôme Rivory ${ }^{4}$, Valérie Hervieu ${ }^{5}$, Jérémie Albouys $^{1}$, Anne Guyot ${ }^{3}$, Thierry Ponchon ${ }^{4,6}$, Denis Sautereau ${ }^{1}$, Sebastien Kerever ${ }^{7}$, Mathieu Pioche ${ }^{4,6}$

submitted 5.12 .2018

accepted after revision 22.5.2019

\section{Bibliography}

DOI https://doi.org/10.1055/a-0965-8531।

Endoscopy International Open 2019; 07: E1166-E1174

(c) Georg Thieme Verlag KG Stuttgart · New York

elSSN 2196-9736

Corresponding author

Jérémie Jacques, MD, Service d'Hépato-Gastro-Entérologie, CHU Dupuytren 87042, Limoges, France

Fax: +33555058733

jeremiejacques@gmail.com

\section{ABSTRACT}

Background and study aims ESD in the colon is more challenging technically than in other locations. Here, we report the first comparative case series of colon ESD using a systematic countertraction strategy using two clips and a rubber band.

Patients and methods Retrospective comparative study of classic versus countertraction colon ESD performed in colon ESD cases collected prospectively at Lyon Edouard Herriot Hospital and Limoges University Hospital from January 2016 until December 2017.

Results The study included 192 cases (control $=76$, countertraction =116). Countertraction using the double clip and rubber band technique versus the control group resulted in a significant decrease in the procedure time ( $94.7 \mathrm{vs.}$ $117 \mathrm{~min} ; P=0.004)$ and significant increases in procedure speed ( 28.2 vs. $16.7 \mathrm{~mm}^{2} / \mathrm{min} ; P<0.0001$ ), en bloc resection rate $(95.7 \%$ vs. $76.3 \%, P<0.0001)$, and $\mathrm{R} 0$ resection rate $(78.5 \%$ vs. $64.5 \%, P=0.04)$.

At an individual operator point of view, results varied between operators but the double clip countertraction strategy significantly increased the en bloc resection rate, $\mathrm{R} 0$ resection rate, and speed of dissection for each of the 4 operators.

Conclusion Systematic countertraction using a double clip and rubber band facilitates colon ESD. This strategy should become the standard for colon ESD.

\section{Introduction}

Endoscopic submucosal dissection (ESD) was developed in Japan to cure superficial gastric neoplasms. ESD has since become the standard of care for low risk of lymph node metastasis superficial neoplasms of the esophagus, stomach, and rectum [1]. For colon lesions, the absolute need for en bloc resection is controversial because of the excellent results that have been obtained with piecemeal endoscopic mucosal resection [2]. ESD in the colon is more challenging technically and risky due to bowel movements, variable gravity, fold anatomy, thinness and fibrosis of the submucosal space, poor scope maneuverability with loop formation, and thinness of the muscularis propria. Good exposure of the submucosal space is critical for safe and quick ESD. We previously reported the use of a simple countertraction technique that uses two clips and a rubber band [3]; here, we report the first comparative case series of colon ESD using this countertraction technique. 

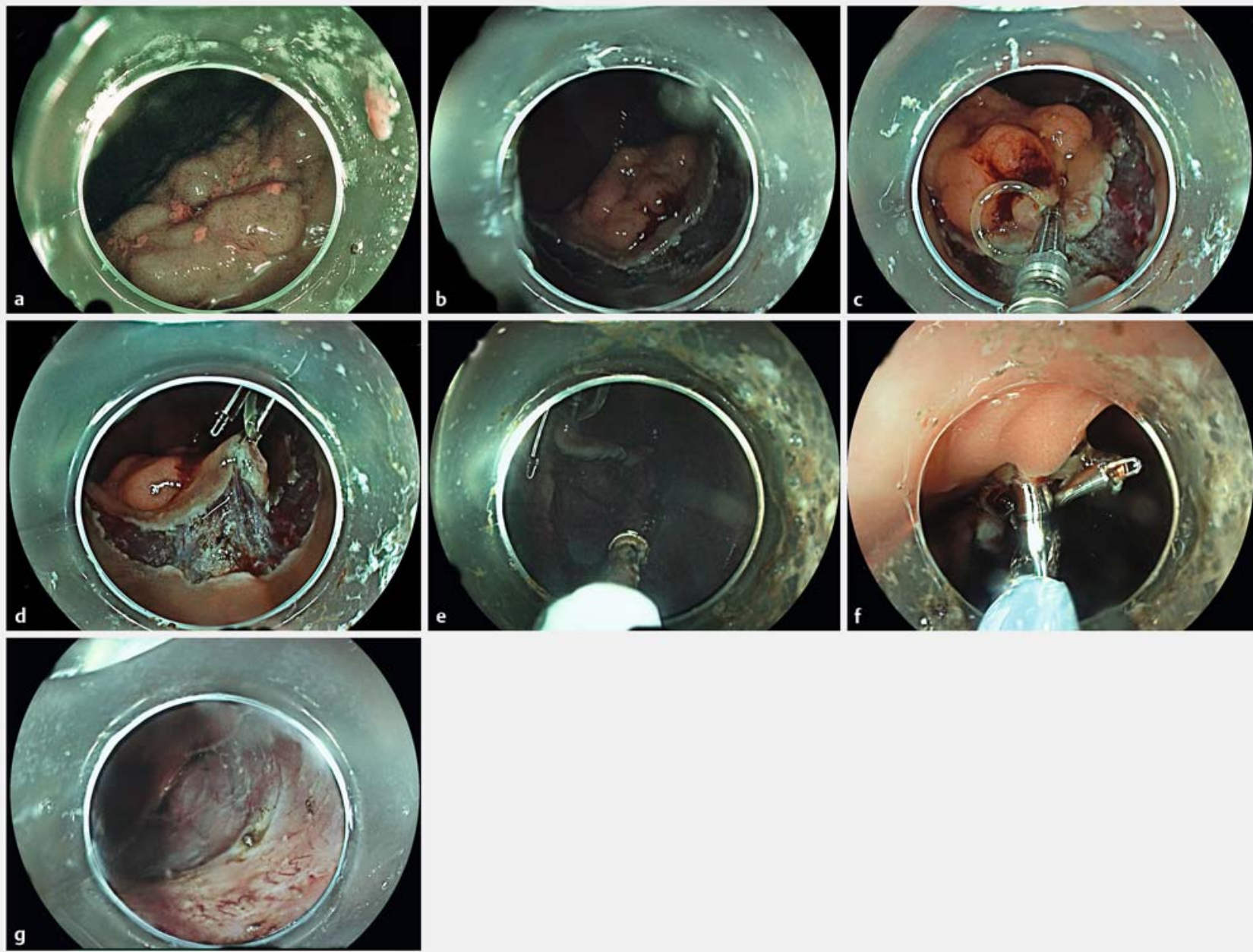

- Fig. 1 Schematic description of the double clip + rubber band countertraction strategy.

\section{Patients and methods}

\section{Study design}

We performed a retrospective comparative study of classic versus countertraction colon ESD performed in colon ESD cases collected prospectively at Lyon Edouard Herriot Hospital and Limoges University Hospital from January 2016 until December 2017.

The ethics committee of Limoges University Hospital approved this retrospective study, and all patients gave informed consent before their procedures ( $\vee$ Video 1 ).

\section{The ESD procedure}

All colon ESDs conducted since March 2017 were performed using the double clip and rubber band countertraction technique. The control group treated from January 2016 to March 2017 underwent "classic ESD".

In the counteraction group, after making a hemicircumferential or circumferential mucosal incision, the first clip was attached to the anal side of the lesion, grasping both the specimen and the rubber band. Fox rubber band $3 \mathrm{D}$ (1/4"), 3-1/2 oz.

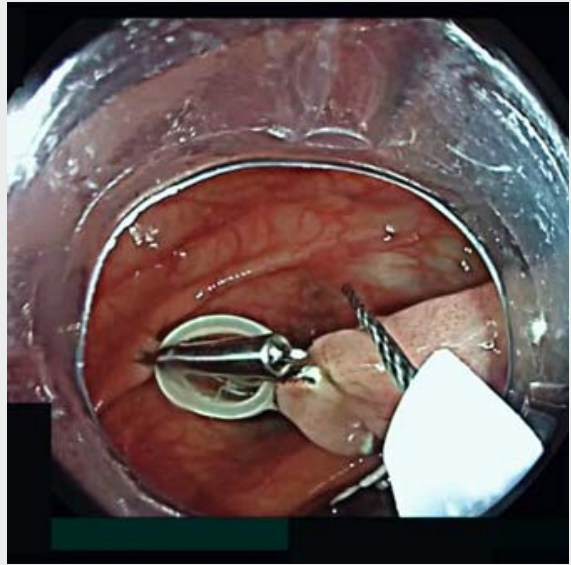

Video 1 Endoscopic resection of the double clip+rubber band countertraction strategy for a large, flat, non-granular LST of the ileocecal valve. 

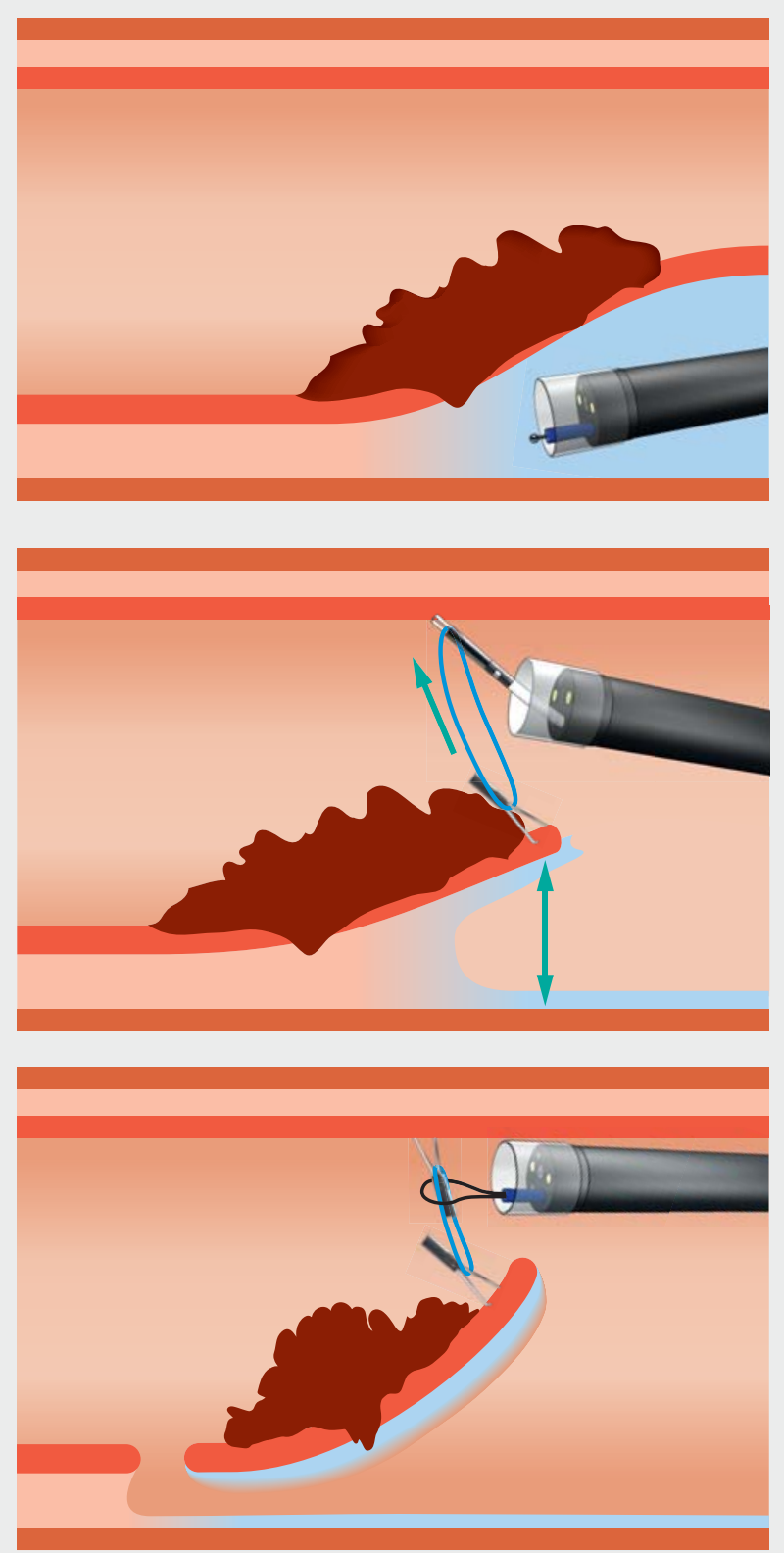

Fig. 2 Description of the procedure.

(ORMCO) and repositionable clips were used. (Boston resolution 360 Boston Scientific USA or Quick clip Pro Olympus USA). The rubber band was grasped by the clip outside the scope and inserted in the working channel of the endoscope.

A second clip was then inserted in the working channel of the scope. The clip grasped the rubber band already attached to the specimen with the first clip and was then placed on the colon wall in front of the lesion to expose the submucosal space. If the orientation needed to be changed, the countertraction clip on the colon wall could be removed with gentle traction using a polypectomy snare $(10 \mathrm{~mm})$ and a new one placed in another direction ( $>$ Fig. 1, $>$ Fig. 2). In cases of allergy, rubber bands without latex were used.
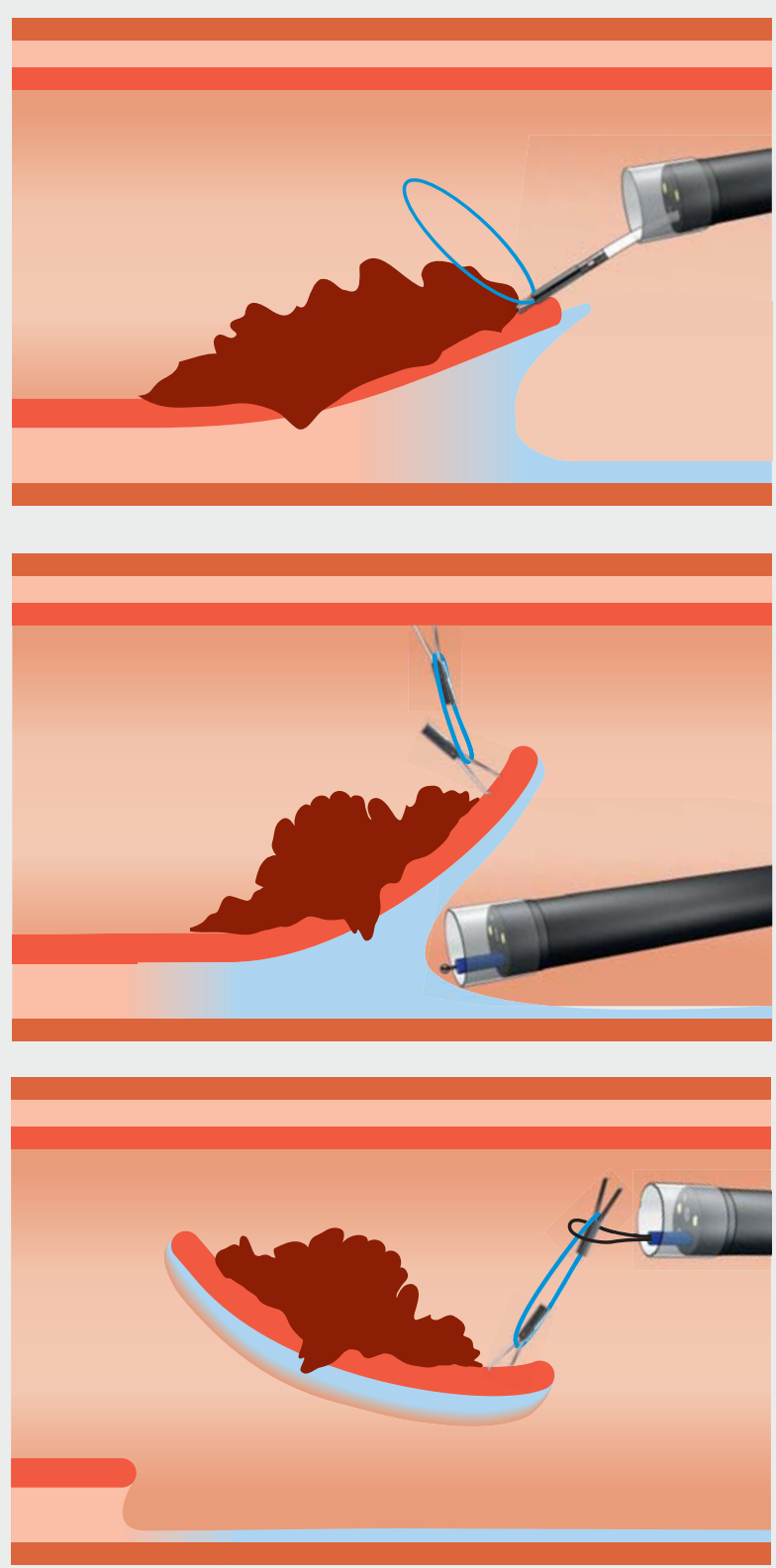

\section{Operator experience}

The procedure was performed by four physicians (JR, RL, MP and J) who had performed at least 100 animal ESDs and 100 human ESDs, including 50 rectal ESDs, but who had no prior experience with colon ESD without supervision.

\section{Materials}

High-definition standard and pediatric colonoscopes and a distal transparent hood were used for the procedures. A $1.5-\mathrm{mm}$ Dual Knife (Olympus, Tokyo, Japan) was used for the procedures. All procedures were performed under $\mathrm{CO}_{2}$ insufflation. 
Injection in the submucosa was performed with glycerol mix or hydroxyethylstarch for all the procedures.

\section{Inclusion criteria}

All colon ESD cases performed between January 2016 and December 2017 were included in this study.

\section{Exclusion criteria}

We excluded patients with expected severe fibrosis under the lesion including recurrent adenomas, those who underwent prior endoscopic resection with incomplete resection, those with polyps exhibiting deep involvement of the appendix (type 2 or 3 in the Toyonaga classification [4]) or located inside the ileocecal valve, and those with lesions complicating ulcerative colitis.

\section{Data analysis}

Specimen size, procedure duration and speed, peri-procedure and post-procedure bleeding, perforation, and en bloc, R0, and curative resections were recorded prospectively. Lesions were characterized according to their location and technical difficulty in the SMSA score [5]

An R0 resection was defined by tumor-free vertical and lateral margins. Curative resection was reported if the specimen met the R0 definition with no risk of lymph node metastasis, such as lymphovascular invasion, undifferentiated type, or presence of budding or submucosal infiltration deeper than $1000 \mu \mathrm{m}$.

The surface area of the specimen was calculated at the end of the procedure from the two largest diameters using the formula [area $\left(\mathrm{mm}^{2}\right)=($ smaller diameter $(\mathrm{mm}) / 2) \times($ larger diameter $(\mathrm{mm}) / 2) \times \pi]$.

The dissection speed was defined as speed $\left(\mathrm{mm}^{2} / \mathrm{min}\right)=$ area $\left(\mathrm{mm}^{2}\right)$ /duration (min).

Optimal ESD was defined as an $\mathrm{R} 0$ resection without perforation with a speed of dissection higher than $15 \mathrm{~mm}^{2} /$ minute. The threshold of $15 \mathrm{~mm}^{2} /$ minute was chosen because it corresponds to the speed needed to resect a $3-\mathrm{cm}$ circular lesion in less than 1 hour.

\section{Statistical analysis}

Study data are presented as medians and interquartile ranges for continuous variables, means (SD) for normally distributed continuous variables, and frequencies and percentages for qualitative variables. Fisher's exact test and $x^{2}$ tests were used for comparisons involving qualitative variables, and the Wilcoxon rank-sum test was used for comparisons involving continuous variables;

All $P$ values were two-tailed, and $P<0.05$ was considered significant. All statistical analyses were performed using R statistical software (R Foundation for Statistical Computing, Vienna, Austria).

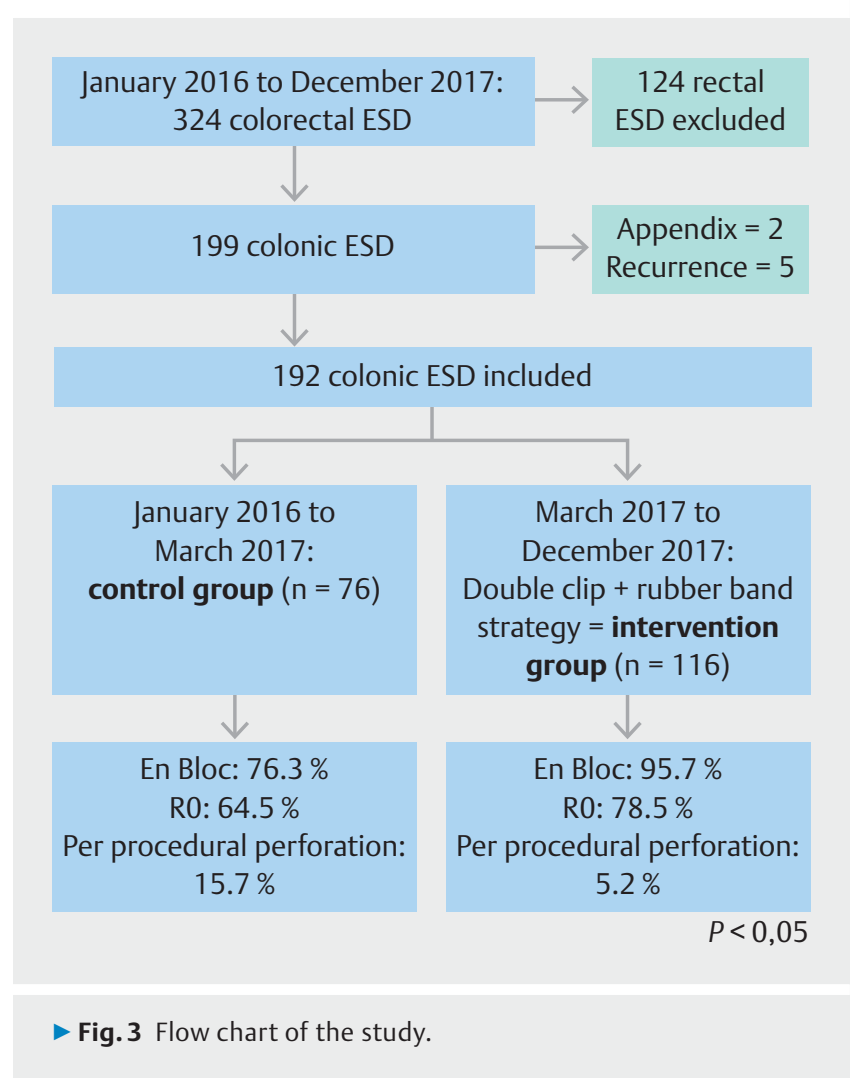

\section{Results}

During the study period, the four physicians performed 324 colorectal ESD and 125 rectal ESD were excluded. Seven more cases were excluded because of deep invasion into the appendix $(n=2)$ or recurrent disease after piecemeal resection $(n=$ 5). Ultimately, 192 cases were included in the study ( $>$ Fig. 3 ).

- Table 1 summarizes characteristics of the lesions. Overall, 109 lesions (56.8\%) were located proximal to the splenic flexure and 150 (78.1\%) were considered very difficult lesions (SMSA 4) [5]. Mean size of the lesions was $53.6 \times 41.5 \mathrm{~mm}$. Mean duration of the procedure was 103 minutes (range $10-$ 383), and mean speed of dissection was $24 \mathrm{~mm}^{2} /$ minute. Comparing the countertraction and control groups ( $\vee$ Table 2 ), the lesions were larger ( 56.2 vs. $49 \mathrm{~mm}, P=0.025)$, more frequently located proximal to the splenic flexure $(62.2 \%$ vs. $47.2 \%)$ in the countertraction than in the control group and more frequently considered SMSA 4 lesions ( $92.2 \%$ vs $56.6 \% P=0.02$ ).

The respective rates of en bloc, R0. and curative resection were $88 \%, 73 \%$, and $69.3 \%$, respectively. Countertraction using the double clip and rubber band technique versus the control group resulted in a significant decrease in procedure time (117,6 min [95\% Cl: 102; 133.3] vs 94,7 min [Cl 95\%: 83.3; 106.1], $P=0.004)$ and significant increases in procedure speed (16.7 $\mathrm{mm}^{2} /$ minute [Cl 95\%: 13.2; 20.1 ] vs $28.2 \mathrm{~mm}_{2} / \mathrm{min}[95 \%$ Cl: 24.1 ; 32.4$] P<0.0001)$, en bloc resection rate $(95.7 \%$ vs. $76.3 \%, P<0.0001)$, and $\mathrm{R} 0$ resection rate $(78.5 \%$ vs. $64.5 \%, P=$ 0.04).

Perforation occurred in $18(9.4 \%)$ cases, of which only one required surgery $(0.5 \%)$ to treat peritonitis despite endoscopic 
- Table 1 Summary of colon ESD cases included in the study.

\begin{tabular}{|c|c|c|}
\hline & Data & N (\%) \\
\hline \multirow[t]{2}{*}{ Gender } & Men & $110(57.3 \%$ \\
\hline & Women & $82(42.7 \%)$ \\
\hline \multicolumn{3}{|l|}{ Age (years) } \\
\hline \multirow[t]{2}{*}{ Center } & Lyon & $113(58.9 \%)$ \\
\hline & Limoges & $79(41.1 \%)$ \\
\hline \multirow[t]{4}{*}{ Physician } & 1 & $94(49 \%)$ \\
\hline & 2 & $19(9.9 \%)$ \\
\hline & 3 & $38(19.8 \%)$ \\
\hline & 4 & $41(21.3 \%)$ \\
\hline \multirow[t]{2}{*}{ Group } & Pocket & $76(39.6 \%)$ \\
\hline & Traction & $116(60.4 \%)$ \\
\hline \multirow[t]{3}{*}{ Lesion } & Polyp & $13(7.6 \%)$ \\
\hline & LST-G & $108(63.5 \%)$ \\
\hline & LST-NG & $49(18.8 \%)$ \\
\hline \multirow[t]{8}{*}{ Localization } & Sigmoid & $54(28.1 \%)$ \\
\hline & Left colon & $17(8.9 \%)$ \\
\hline & Splenic flexure & $11(5.7 \%)$ \\
\hline & Transverse & $16(8.3 \%)$ \\
\hline & Hepatic flexure & $23(12 \%)$ \\
\hline & Right colon & $41(21.3 \%)$ \\
\hline & Ileocecal valve & $4(2.1 \%)$ \\
\hline & Cecum & $26(13.5 \%)$ \\
\hline \multicolumn{2}{|c|}{ Above splenic flexure } & 109 (56.8\%) \\
\hline Duration (mir & & $103( \pm 63)$ \\
\hline
\end{tabular}

closure. Four (2.1\%) post-procedural perforations also occurred, all of which required surgical intervention for peritonitis. The double clip technique ( $\triangleright$ Table 2 ) also decreased the perprocedure perforation rate three-fold compared with the rubber band technique (5.2\% vs. $15.7 \%$ ). Double clip strategy also considerably increases the "optimal ESD" rate from $26.3 \%$ to $53 \%(P=0.0003)$.

Two patients ( $1 \%$ ) had small local recurrences at the first endoscopic follow-up after $\mathrm{R} 1$ resection, which were easily managed by endoscopic resection.

At an individual operator point of view ( $\triangleright$ Table 3 ), results varied between operators but the double clip countertraction strategy significantly increased en bloc and R0 resection rates and speed of dissection for each of the four operators. It also decreased the perforation rate for each operator.

No adverse events linked to clip positioning or removal occurred during the study. Nevertheless, one specimen (1/192, $0.5 \%$ ) was damaged by the clip countertraction that cut the margin.
- Table 1 (Continuation)

\begin{tabular}{|l|c|c|}
\hline & Data & N (\%) \\
\hline Large diameter $(\mathrm{mm})$ & $53.6( \pm 19)$ \\
\hline Small diameter $(\mathrm{mm})$ & & $41.5( \pm 15.7)$ \\
\hline Surface $\left(\mathrm{mm}^{2}\right)$ & & $1952( \pm 1532)$ \\
\hline Speed $\left(\mathrm{mm}^{2} /\right.$ min) & & $24( \pm 20)$ \\
\hline En bloc & & $169(88 \%)$ \\
\hline R0 & & $140(73 \%)$ \\
\hline Curative & & $133(69.3 \%)$ \\
\hline Perforation & & $18(9.4 \%)$ \\
\hline Post-procedural bleeding & $8(4.1 \%)$ \\
\hline Length of stay & & $3( \pm 2.5)$ \\
\hline Anticoagulation & & $27(15.2 \%)$ \\
\hline Antiplatelet & & $37(20.8 \%)$ \\
\hline Pathological analysis & & $3(1.6 \%)$ \\
\hline & LGD & $2(1.1 \%)$ \\
\hline taplasia; SM, submucosal; SSA, sessile serrated adenoma; ESD, endoscopic \\
\hline submucosal dissection
\end{tabular}

\section{Discussion}

Our study is the largest series of ESD performed in the colon (excluding rectum) reported in the Western world. It confirms results from Japan in terms of safety in the countertraction group despite a mean lesion size that is the highest reported in a colonic ESD study [6,7]. Many teams are working on countertraction strategies to facilitate this highly skilled procedure, especially in the colon where ESD is particularly challenging. Indeed, even in eastern countries, colonic ESD is not widely performed due to its technical difficulty, longer procedure time, and higher risk of complications. Our strategy considerably improved our technical results, doubling the speed and decreasing the perforation rate three-fold, as well as the oncological results, with significant increases in en bloc and $\mathrm{R} 0$ resection rates. This benefit is underscored even more by the fact that lesions in the traction group were more technically difficult (more often SMSA 4 and proximal to the splenic flexure). The 
- Table 2 Comparison of the countertraction and control groups.

\begin{tabular}{|c|c|c|c|c|}
\hline & Data & Pocket (76) & Traction (116) & $P$ \\
\hline \multirow[t]{2}{*}{ Gender } & Men & $48(63 \%)$ & $62(53 \%)$ & 0.23 \\
\hline & Women & $28(37 \%)$ & $54(47 \%)$ & \\
\hline Age (years) & & $67.2( \pm 9)$ & $67( \pm 9)$ & \\
\hline \multirow[t]{2}{*}{ Center } & Limoges & $30(39.5 \%)$ & $49(42.3 \%)$ & 0.77 \\
\hline & Lyon & $46(60.5 \%)$ & $67(57.7 \%)$ & \\
\hline \multirow[t]{4}{*}{ Physician } & 1 & $41(54 \%)$ & $53(45.7 \%)$ & 0.56 \\
\hline & 2 & $5(6.6 \%)$ & $14(12.1 \%)$ & \\
\hline & 3 & $14(18.4 \%)$ & $24(20.7 \%)$ & \\
\hline & 4 & $16(21 \%)$ & $25(21.6 \%)$ & \\
\hline \multirow[t]{3}{*}{ Lesion } & Polyp & $8(12.1 \%)$ & $5(4.8 \%)$ & 0.17 \\
\hline & LST-G & $42(63.6 \%)$ & $66(63.5 \%)$ & \\
\hline & LST-NG & $16(24.3 \%)$ & $33(31.7 \%)$ & \\
\hline \multirow[t]{8}{*}{ Localization } & Sigmoid & $26(34.2 \%)$ & $28(24.1 \%)$ & 0.53 \\
\hline & Left colon & $8(10.5 \%)$ & $9(7.8 \%)$ & \\
\hline & Splenic flexure & $5(6.6 \%)$ & $6(5.1 \%)$ & \\
\hline & Transverse & $8(10.5 \%)$ & $8(6.9 \%)$ & \\
\hline & Hepatic flexure & $7(9.2 \%)$ & $16(13.8 \%)$ & \\
\hline & Right colon & $13(17.1 \%)$ & $28(24.1 \%)$ & \\
\hline & Ileocecal valve & $2(2.6 \%)$ & $2(1.7 \%)$ & \\
\hline & Cecum & $7(9.2 \%)$ & $19(16.4 \%)$ & \\
\hline \multicolumn{2}{|l|}{ Above splenic flexure } & $39(51.3 \%)$ & $44(38 \%)$ & 0.075 \\
\hline Duration (min) & & $117( \pm 63)$ & $94.7( \pm 63)$ & 0.004 \\
\hline \multicolumn{2}{|l|}{ Large diameter (mm) } & $49( \pm 16)$ & $56.2( \pm 19)$ & 0.025 \\
\hline \multicolumn{2}{|l|}{ Small diameter (mm) } & $38.7( \pm 13.5)$ & $43.1( \pm 15.8)$ & 0.14 \\
\hline Surface $\left(\mathrm{mm}^{2}\right)$ & & $1633( \pm 1088)$ & $2135( \pm 1540)$ & 0.065 \\
\hline Speed $\left(\mathrm{mm}^{2} / \mathrm{min}\right)$ & & $16.7( \pm 13.7)$ & $28.2( \pm 20.4)$ & $<0.0001$ \\
\hline En bloc & & $58(76.3 \%)$ & $111(95.7 \%)$ & $<0.0001$ \\
\hline Ro & & $49(64.5 \%)$ & $91(78.5 \%)$ & 0.046 \\
\hline Curative & & $45(59.2 \%)$ & $88(75.9 \%)$ & 0.017 \\
\hline Perforation & & $12(15.7 \%)$ & $6(5.2 \%)$ & 0.021 \\
\hline \multicolumn{2}{|l|}{ Post procedural bleeding } & $4(5.3 \%)$ & $4(3.5 \%)$ & 0.72 \\
\hline \multicolumn{2}{|l|}{ Length of stay } & 3.5 & 2.7 & 0.013 \\
\hline \multicolumn{2}{|l|}{ Anticoagulation } & $11(17.2 \%)$ & $16(14 \%)$ & 0.66 \\
\hline Antiplatelet & & $9(14 \%)$ & $28(24.6 \%)$ & 0.12 \\
\hline \multicolumn{5}{|l|}{ Pathological analysis } \\
\hline & LGD & $20(27.4 \%)$ & $39(34 \%)$ & 0.53 \\
\hline & HGD & $25(34.3 \%)$ & $48(41.7 \%)$ & \\
\hline & IM Cancer & $16(22 \%)$ & $14(12.2 \%)$ & \\
\hline & SM superficial cancer & $1(1.4 \%)$ & $4(3.5 \%)$ & \\
\hline & SM deep cancer & $8(11 \%)$ & $8(7 \%)$ & \\
\hline
\end{tabular}


- Table 2 (Continuation)

\begin{tabular}{|l|c|c|c|c|}
\hline & Data & Pocket (76) & Traction (116) & \multicolumn{1}{|c|}{0} \\
\hline & T2 & $3(4.1 \%)$ & $0(0 \%)$ \\
\hline & SSA & $0(0 \%)$ & $2(1.7 \%)$ \\
\hline Optimal ESD & & $20(26.3 \%)$ & $61(53 \%)$ & 0.0003 \\
\hline SMSA 4 & & $43(56.6 \%)$ & $107(92.2 \%)$ & 0.02 \\
\hline
\end{tabular}

LST-G, laterally spreading granular; LST-NG, laterally spreading non-granular; LGD, low-grade dysplasia; HGD, high-grade dysplasia; IM, ; SM, submucosal; SSA, sessile serrated adenoma; SMSA, size, morphology, site access.

- Table 3 Individual comparison of the countertraction and the control group.

\begin{tabular}{|c|c|c|c|c|}
\hline & & Control (76) & Traction (116) & $p$ \\
\hline \multirow[t]{4}{*}{ Operators } & 1 & $41(54 \%)$ & $53(45.7 \%)$ & \\
\hline & 2 & $5(6.6 \%)$ & $14(12.1 \%)$ & \\
\hline & 3 & $14(18.4 \%)$ & $24(20.7 \%)$ & \\
\hline & 4 & $16(21 \%)$ & $25(21.5 \%)$ & \\
\hline \multirow[t]{4}{*}{ Above splenic flexure } & 1 & $22(53.7 \%)$ & $36(68 \%)$ & $P=0.12$ \\
\hline & 2 & $1(20 \%)$ & $9(64.3 \%)$ & $P=0.08$ \\
\hline & 3 & $6(43 \%)$ & $11(46 \%)$ & $P=0.86$ \\
\hline & 4 & $8(50 \%)$ & $16(64 \%)$ & $P=0.37$ \\
\hline \multirow[t]{4}{*}{ Duration (min) } & 1 & 109 & 63 & $P=0.0002$ \\
\hline & 2 & 105 & 83.1 & $P=0.46$ \\
\hline & 3 & 120 & 126 & $P=0.82$ \\
\hline & 4 & 143.4 & 135 & $P=0.72$ \\
\hline \multirow[t]{4}{*}{ Large diameter (mm) } & 1 & 52.4 & 56.1 & $P=0.35$ \\
\hline & 2 & 40 & 61.1 & $P=0.08$ \\
\hline & 3 & 40 & 55 & $P=0.0073$ \\
\hline & 4 & 48.9 & 54 & $P=0.39$ \\
\hline \multirow[t]{4}{*}{ Small diameter (mm) } & 1 & 40.7 & 41.9 & $P=0.73$ \\
\hline & 2 & 33 & 49.2 & $P=0.08$ \\
\hline & 3 & 33 & 43 & $P=0.02$ \\
\hline & 4 & 39.6 & 42 & $P=0.66$ \\
\hline \multirow[t]{4}{*}{ Surface $\left(\mathrm{mm}^{2}\right)$} & 1 & 1819 & 2053 & $P=0.43$ \\
\hline & 2 & 1252 & 2665 & $P=0.06$ \\
\hline & 3 & 1102 & 2140 & $P=0.017$ \\
\hline & 4 & 1661 & 2022 & $P=0.45$ \\
\hline \multirow[t]{4}{*}{ Vitesse $\left(\mathrm{mm}^{2} / \mathrm{min}\right)$} & 1 & 20.1 & 38.18 & $P=0.0002$ \\
\hline & 2 & 13 & 33.3 & $P=0.016$ \\
\hline & 3 & 11 & 17 & $P=0.017$ \\
\hline & 4 & 12.4 & 15.3 & $P=0.26$ \\
\hline \multirow[t]{3}{*}{ Monobloc } & 1 & $31(75.7)$ & $50(94.3)$ & $P=0.005$ \\
\hline & 2 & $5(100 \%)$ & 13 (93\%) & $P=1$ \\
\hline & 3 & 10 (71\%) & 23 (95.8\%) & $P=0.03$ \\
\hline
\end{tabular}


Table 3 (Continuation)

\begin{tabular}{|c|c|c|c|c|}
\hline & & Control (76) & Traction (116) & $p$ \\
\hline & 4 & $12(75 \%)$ & $25(100 \%)$ & $P=0.008$ \\
\hline \multirow[t]{4}{*}{ Ro } & 1 & $29(70.7 \%)$ & $45(85 \%)$ & $P=0.06$ \\
\hline & 2 & $4(80 \%)$ & $8(57.1 \%)$ & $P=0.6$ \\
\hline & 3 & $8(57 \%)$ & $19(79.1 \%)$ & $P=0.14$ \\
\hline & 4 & $8(50 \%)$ & $19(76 \%)$ & $P=0.08$ \\
\hline \multirow[t]{4}{*}{ Perforation } & 1 & $4(9.7 \%)$ & $2(3.8 \%)$ & $P=0.25$ \\
\hline & 2 & $1(20 \%)$ & $1(7.1 \%)$ & $P=0.4$ \\
\hline & 3 & $3(21 \%)$ & $2(8.3 \%)$ & $P=0.25$ \\
\hline & 4 & $4(25 \%)$ & $1(4 \%)$ & $P=0.045$ \\
\hline \multirow[t]{4}{*}{ Post-procedural bleeding } & 1 & $3(7.3 \%)$ & $1(2 \%)$ & $P=0.31$ \\
\hline & 2 & $0(0 \%)$ & $1(7.1 \%)$ & $P=1$ \\
\hline & 3 & $0(0 \%)$ & $1(4.1 \%)$ & $P=1$ \\
\hline & 4 & $1(6.2 \%)$ & $1(4.1 \%)$ & $P=1$ \\
\hline \multirow[t]{4}{*}{ Optimal ESD } & 1 & $16(39 \%)$ & $35(66 \%)$ & $P=0.01$ \\
\hline & 2 & $0(0 \%)$ & $8(57 \%)$ & $P=0.044$ \\
\hline & 3 & $1(7.1 \%)$ & $11(46 \%)$ & $P=0.08$ \\
\hline & 4 & $3(18.7 \%)$ & $8(32 \%)$ & $P=0.48$ \\
\hline
\end{tabular}

strengths of this strategy are its reproducibility, adaptability, and simplicity.

As was previously reported, our results confirm inter-operator variability of ESD results. However, this strategy improved all oncological and technical results in each operator at an individual level.

A learning curve effect could be argued in discussion of our impressive results. However, the four operators already had significant expertise at the beginning of the study with more than 100 ESDs including 50 rectal ESDs and more than 100 animal ESDs. This expertise is over and above that classically required for proficiency with colonic ESD.

Adaptability of the strategy is the main quality that distinguishes it from other traction devices. Removing and repositioning the clip on the colon wall is easy using a polypectomy snare and allows modification of countertraction during the procedure to optimize exposure of the submucosal space. Moreover, elasticity of the rubber band plays a role in this adaptability. Indeed, increasing insufflation increases the countertraction, while exsufflation of the colon decreases countertraction.

This countertraction strategy is safe and does not damage the colon when positioning or removing the clip. It is also safe for the specimen, as only one specimen was torn as a consequence of the countertraction.

The rubber band and clip can pass through the working channel of the colonoscope, unlike with several other reported traction systems, therefore, the scope does not have to be re- moved using this strategy. This is important in the case of difficult colonoscopies or lesions in difficult positions.

The efficiency of this countertraction strategy has altered our approach to colorectal ESD. Before using it, the choice of strategy was very important for colon ESD in terms of checking the effects of gravity and the maneuverability of the scope, creating a small mucosal incision to position quickly beneath the lesion (pocket creation method [8] or tunnel ESD [9]), and trying to make the pocket parallel to and not in front of the folds. With our countertraction strategy, the most limiting factor is scope maneuverability. We quickly make a circumferential incision and then position the countertraction, because leakage of the injected fluid is not a problem as the submucosal fibers are stretched and perfectly exposed.

Several limitations of this study have to be mentioned, the first of which is the retrospective design. However, the two centers that participated had a prospective consecutive database and since their first publication about clip and rubber band strategy, all cases have been performed using this strategy. Moreover, because the control group was the first 80 colonic cases in the two centers, a learning curve effect could be argued. However, all operators had already performed more than 100 animals ESDs and 100 human ESDs, including 50 rectal cases, and could not be considered as trainees in ESD. We decided not to perform a randomized study because of ethical limitations, considering the big difference in results between the two groups. 
Moreover our results are in keeping with results recently reported by the team of Professor Yamamoto with the pocket creation method (PCM) strategy [10]. Speed of resection in the PCM group in the Japanese study was lower than in our study $\left(23.5 \mathrm{~mm}^{2} /\right.$ minute) although Professor Yamamoto's group is one of the most famous teams of colorectal endoscopists in the world.

Rectal is much easier than colonic ESD because of perfect scope maneuverability, easy use of gravitation, larger submucosal space, possibility of using the gastroscope, and less likelihood of perforation due to the under-the-peritoneum location. Therefore, we excluded rectal cases from our study as had been advocated recently by an European expert group on ESD [11]. However, we regularly use this strategy in rectal cases. It does not improve en bloc or $\mathrm{R} 0$ resection rates, which are already very high in our centers, but it clearly improves procedure speed.

Other teams have reported on ESD with traction devices that use a rubber band. In a pig gastric model, Parra blanco et al used a rubber band with two clips attached on the specimen like a wallet [12]. Professor Sakamoto's team in Japan reported an advantage in speed of resection with their SO-clip [13, 14] that was similar to that with our traction device. The Japanese device combines a rubber band with a spring and two clips but it is not available in western countries even though rubber bands are widely available.

\section{Conclusion}

In conclusion, systematic countertraction using a double clip and rubber band facilitates colon ESD. It doubles the speed of dissection, decreases the perforation rate three-fold, and increases en bloc and $\mathrm{R} 0$ resection rates. This strategy should become the standard for colon ESD. These results will increase debate about whether piecemeal endoscopic mucosal resection or ESD is the best endoscopic resection procedure for large superficial neoplastic lesions of the colon $[15,16]$.

Competing interests

Pioche Mathieu, Rivory Jérome, Ponchon Thierry: consultants for Olympus

\section{References}

[1] Pimentel-Nunes P, Dinis-Ribeiro M, Ponchon T et al. Endoscopic submucosal dissection: European Society of Gastrointestinal Endoscopy (ESGE) Guideline. Endoscopy 2015; 47: 829-854
[2] Bahin FF, Heitman S], Rasouli KN et al. Wide-field endoscopic mucosal resection versus endoscopic submucosal dissection for laterally spreading colorectal lesions: a cost-effectiveness analysis. Gut 2018; 67: $1965-1973$

[3] Jacques ], Charissoux A, Legros R et al. Double-clip counter-traction using a rubber band is a useful and adaptive tool for colonic endoscopic submucosal dissection. Endoscopy 2018; 50: 179-181

[4] Jacob H, Toyonaga T, Ohara Y et al. Endoscopic submucosal dissection of cecal lesions in proximity to the appendiceal orifice. Endoscopy 2016; 48: 829-836

[5] Gupta S, Miskovic D, Bhandari P. A novel method for determining the difficulty of colonoscopic polypectomy. Frontline Gastroenterol 2013; 4: $244-248$

[6] Sidhu M, Tate DJ, Desomer L et al. The size, morphology, site, and access score predicts critical outcomes of endoscopic mucosal resection in the colon. Endoscopy 2018; 50: 684-692

[7] Saito Y, Uraoka T, Yamaguchi Y k et al. A prospective, multicenter study of 1111 colorectal endoscopic submucosal dissections (with video). Gastrointest Endosc 2010; 72: 1217-1225

[8] Kanamori A, Nakano M, Kondo M et al. Clinical effectiveness of the pocket-creation method for colorectal endoscopic submucosal dissection. Endosc Int Open 2017; 5: E1299-E1305

[9] Pioche M, Rivory J, Lépilliez V et al. Tunnel-and-bridge strategy for rectal endoscopic submucosal dissection: tips to allow strong countertraction without clip and line. Endoscopy 2017; 49: E123-E124

[10] Takezawa T, Hayashi Y, Shinozaki S et al. The Pocket-creation method facilitates colonic endoscopic submucosal dissection (with video). Gastrointest Endosc 2019; 89: 1045 - 1053

[11] Fuccio L, Bhandari P, Maselli R et al. Ten quality indicators for endoscopic submucosal dissection: what should be monitored and reported to improve quality. Ann TransI Med 2018; 6: 262

[12] Parra-Blanco A, Nicolas D, Arnau MR et al. Gastric endoscopic submucosal dissection assisted by a new traction method: the clip-band technique. A feasibility study in a porcine model (with video). Gastrointest Endosc 2011; 74: 1137 -1141

[13] Sakamoto N, Osada T, Shibuya T et al. Endoscopic submucosal dissection of large colorectal tumors by using a novel spring-action $\mathrm{S}-\mathrm{O}$ clip for traction (with video). Gastrointest Endosc 2009; 69: 1370 1374

[14] Ritsuno H, Sakamoto N, Osada T et al. Prospective clinical trial of traction device-assisted endoscopic submucosal dissection of large superficial colorectal tumors using the S-O clip. Surg Endosc 2014; 28: $3143-3149$

[15] Saito Y, Bhatt A, Matsuda T. Colorectal endoscopic submucosal dissection and its journey to the West. Gastrointest Endosc 2017; 86: $90-92$

[16] Heitman SJ, Bourke MJ. Endoscopic submucosal dissection and EMR for large colorectal polyps: "the perfect is the enemy of good". Gastrointest Endosc 2017; 86: 87 - 89 